(1)

CrossMark

\title{
COVID-19 in Italy: passing through bitter waters
}

\author{
To the Editor:
}

The catastrophic impact of the coronavirus disease 2019 (COVID-19) epidemic in Italy has previously been described $[1,2]$. In a recent editorial, NAVA et al. [3] paid a well-deserved tribute to the almost 200 healthcare workers who succumbed to COVID-19 in the country in less than 3 months since the first case was reported. We would like to contribute with some considerations on the shortcomings of Italy's response to the pandemic.

Around the first COVID-19 cluster in northern Italy, between the regions of Lombardy and Emilia-Romagna, the caseload explosion has been abrupt [4]. Resources quickly became insufficient to provide adequate assistance to all patients [5] As the system became progressively overwhelmed, the death toll started to rise.

During these weeks, working among the communities paying the highest price to the epidemic, we have witnessed the relentless commitment of healthcare personnel at all levels. It has been at once moving and disheartening to observe them struggling to cope with unbearable workloads in a system that was not prepared to support them. Faced with exhausting shifts and often without adequate personal protective equipment, healthcare workers have been unsurprisingly affected by high rates of infection and death [6]. Indeed, as shown by NAVA et al.[3], 65\% of the casualties among medical doctors occurred in the two aforementioned regions.

Obvious reasons for Italy's inadequate outbreak response are years of public sector neglect, increased private expenditure and healthcare budget cuts by governments of all political affiliations [7]. Other major shortfalls stem, in our opinion, from the extreme regionalisation of healthcare, which has led to fragmentation of the decision-making process, increased inequalities and a lack of national coordination [8].

For instance, COVID-19 testing policies vary widely in Italy: some regions perform mass contact tracing and outreach activities, while others prioritise severely sick patients. The role of general practitioners in outbreak response activities also differs substantially across the country. This heterogeneity, coupled with ambiguous communication, has generated inefficiencies and confusion.

Resource allocation during the emergency was similarly impacted, particularly with regard to the management of intensive care unit (ICU) needs. As previously highlighted, Italy only had a modest number of ICU beds [9]. During recent years, this number has been progressively tapered due to budget necessities, despite repeated warning by experts [10]; this meant that the country was completely unprepared for a high burden of patients who required intensive support. Major differences between regions, even those neighbouring one another, in terms of respiratory equipment availability were obvious on everyday news. Nevertheless, inter-regional collaboration was limited. Most patient transfers to relieve overwhelmed ICUs were performed inside the same region, or towards foreign countries.

Finally, the lack of standardisation also affected patient management, which was guided by regional, not national, guidelines. Participation in clinical trials and access to investigational drugs were easier for bigger centres and university hospitals, where greater research experience and manpower facilitated their implementation.

To quote a famous colleague, Doctor Van Helsing from Bram Stoker's Dracula, we will have to pass through the bitter waters before reaching the sweet. Once there, though, this historic opportunity for

@ERSpublications

The COVID-19 epidemic in Italy has shown many shortcomings in the national healthcare system but it also represents a historic opportunity to reinforce central healthcare governance and reduce inequalities across the country https://bit.ly/3gaP9Qi

Cite this article as: Guglielmetti L, Chiesi S. COVID-19 in Italy: passing through bitter waters. Eur Respir J 2020; 56: 2001812 [https://doi.org/10.1183/13993003.01812-2020]. 
reform should be seized: we should strengthen our public healthcare system, reinforce central governance, reduce inequalities across regions and go back to just hospitals rather than "aziende ospedaliere" (hospital companies). Only then will we be ready to react efficiently to the next pandemic threat while adequately protecting our healthcare workers [1].

Lorenzo Guglielmetti $\circledast^{1,2,3}$ and Sheila Chiesi $\oplus^{4}$

${ }^{1}$ Infectious Diseases Unit, Piacenza Hospital, Piacenza, Italy. ${ }^{2}$ APHP, Sorbonne Université, Site Pitié-Salpêtrière, Centre National de Référence des Mycobactéries et de la Résistance des Mycobactéries aux Antituberculeux, Paris, France. ${ }^{3}$ Sorbonne Université, INSERM, U1135, Centre d'Immunologie et des Maladies Infectieuses, Cimi-Paris, équipe 2, Paris,

France. ${ }^{4}$ SPedali Civili’ Hospital of Brescia, Brescia, Italy.

Correspondence: Lorenzo Guglielmetti, Laboratoire de Bactériologie-Hygiène, Faculté de Médecine Sorbonne Université, 91 Boulevard de l'hôpital, 75634 Paris Cedex 13, France. E-mail: lorenzo.guglielmetti@aphp.fr

Received: 15 May 2020 | Accepted: 15 May 2020

Conflict of interest: None declared.

\section{References}

1 Nacoti M, Ciocca A, Giupponi A, et al. At the epicenter of the Covid-19 pandemic and humanitarian crises in Italy: changing perspectives on preparation and mitigation. NEJM Catal 2020; https://doi.org/10.1056/CAT.20. 0080 .

2 Rosenbaum L. Facing Covid-19 in Italy - ethics, logistics, and therapeutics on the epidemic's front line. $N$ Engl J Med 2020; 382: 1873-1875.

Nava S, Tonelli R, Clini E. An Italian sacrifice to COVID-19 epidemic. Eur Respir J 2020; 55: 2001445.

Remuzzi A, Remuzzi G. COVID-19 and Italy: what next? Lancet 2020; 395: 1225-1228. Truog RD, Mitchell C, Daley GQ. The toughest triage - allocating ventilators in a pandemic. N Engl J Med 2020; 382: 1973-1975.

6 Istituto Superiore di Sanità. Integrated surveillance of COVID-19 in Italy. https://www.epicentro.iss.it/en/ coronavirus/bollettino/Infografica_4maggio\%20ENG.pdf Date last updated: 13 May 2020. Date last accessed: 15 May 2020.

7 Armocida B, Formenti B, Ussai S, et al. The Italian health system and the COVID-19 challenge. Lancet Public Health 2020; 5: e253.

8 Neri S. Economic crisis, decentralisation and health inequalities: the case of Italy. In: Tavares AI, ed. Universal Health Coverage. IntechOpen, 2019. [https://doi.org/10.5722/intechopen.89006].

9 Boccia S, Ricciardi W, Ioannidis JPA. What other countries can learn from Italy during the COVID-19 pandemic JAMA Intern Med 2020; in press [https://doi.org/10.1001/jamainternmed.2020.1447].

10 Green ST, Cladi L. Cassandra's curse and covid-19: why do governments listen to businesses over doctors? $B M$ ) 2020; 369: $\mathrm{m} 1852$. 